\title{
Moroccan Climate in the Present and Future: Combined View from Observational Data and Regional Climate Scenarios
}

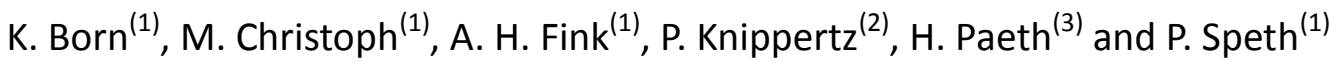 \\ (1) Institute for Geophysics and Meteorology, University Cologne, Germany. \\ (2) Institute for Physics of the Atmosphere, Johannes Gutenberg University, Mainz, Germany.
}

(3) Institute for Geography, University Würzburg, Germany.

\section{Introduction}

Morocco is located between the arid regions of the western Sahara and the moderate Mediterranean and Atlantic regions. Landscape types reach from flat areas in the north-western part to high-mountain areas in the Atlas and Rif. Therefore, we can find a large variety of climates ranging from moderate humid and subhumid climates at the northern slope of the High Atlas over mountain climates to semi-arid and arid climates south of the Atlas. In this tension field, agricultural production and local economy depend very much on water availability, and thus, mainly on rainfall variability. In the past, periods of successive dry years have repeatedly shown the vulnerability to water scarcity, which results in threatened livelihoods of farmers and nomad families living from pasturing. This leads to a stream of migrants heading towards the large cities at the Moroccan coast and even to Europe. In order to counteract the peril of water scarcity, regional planning greatly benefits from information on future climate variability. Of course, the assessment of future climate scenarios in this very heterogeneous region is still a challenge for the climate research community. In this study, the actual state of climate research in IMPETUS West-Africa with respect to rainfall and temperature variability and of research on future climate scenarios is illustrated.

We start with an overview of available information from observational data and a few remarks on their quality. In the second part, results of regional climate modelling (RCM) are discussed with respect to future climate variability especially in regions south of the Atlas Mountains, where the water stress is clearly the limiting factor of agricultural production.

\section{Moroccan Climate: A Short Survey of Observational Data}

An analysis of climate and climate variability always starts with the acquisition of observational information in the region of interest. In Morocco, the density and quality of observations is better than in most other parts of Northern Africa, but still relatively sparse when we think of the spatial heterogeneity of climates. The first and most important source of information stems from SYNOP weather stations, which contribute to the WMO network and deliver data of a relatively high quality standard for several decades now. Unfortunately, most stations in Morocco and the western parts of Algeria are located north of the Atlas Mountains, which leaves a lack of information exactly in the southern region, where the impact of a climate shift is expected to be very strong (Fig. 1). The SYNOP data can be extended by information from individual climate stations operated by regional water management facilities and also by IMPETUS West-Africa, but the quality standard and temporal completeness of these data is not as high as for SYNOPs. Therefore, these data are mainly used to control the quality of derived climate products and do not contribute to the description of regional climates in Morocco.

In order to generate spatially distributed information on near-surface climates, the observations have to be interpolated with adequate statistical techniques. Two projects have produced world-wide data sets of climate-related meteorological parameters from a large number of available observations, which have a spatial resolution of at least $0.5^{\circ}$ longitude and latitude. These are climate data from the Climate Research Unit of the University of East Anglia, hereafter called CRU, in the version TS 2.1 for the period 1901-2002 (Mitchell and Jones, 2005), and the VASCLIMO data (Beck et. al., 2005), which contain only precipitation data for the period 1951-2000. Both data sets contain monthly averages. The VASCLIMO data were subject to a more rigorous quality control and can therefore be used to improve the CRU data, where only information from the period $1951-2000$ is requested. At the moment, these two data sets represent the most reliable long-term rainfall information despite the problems with data coverage described above. 


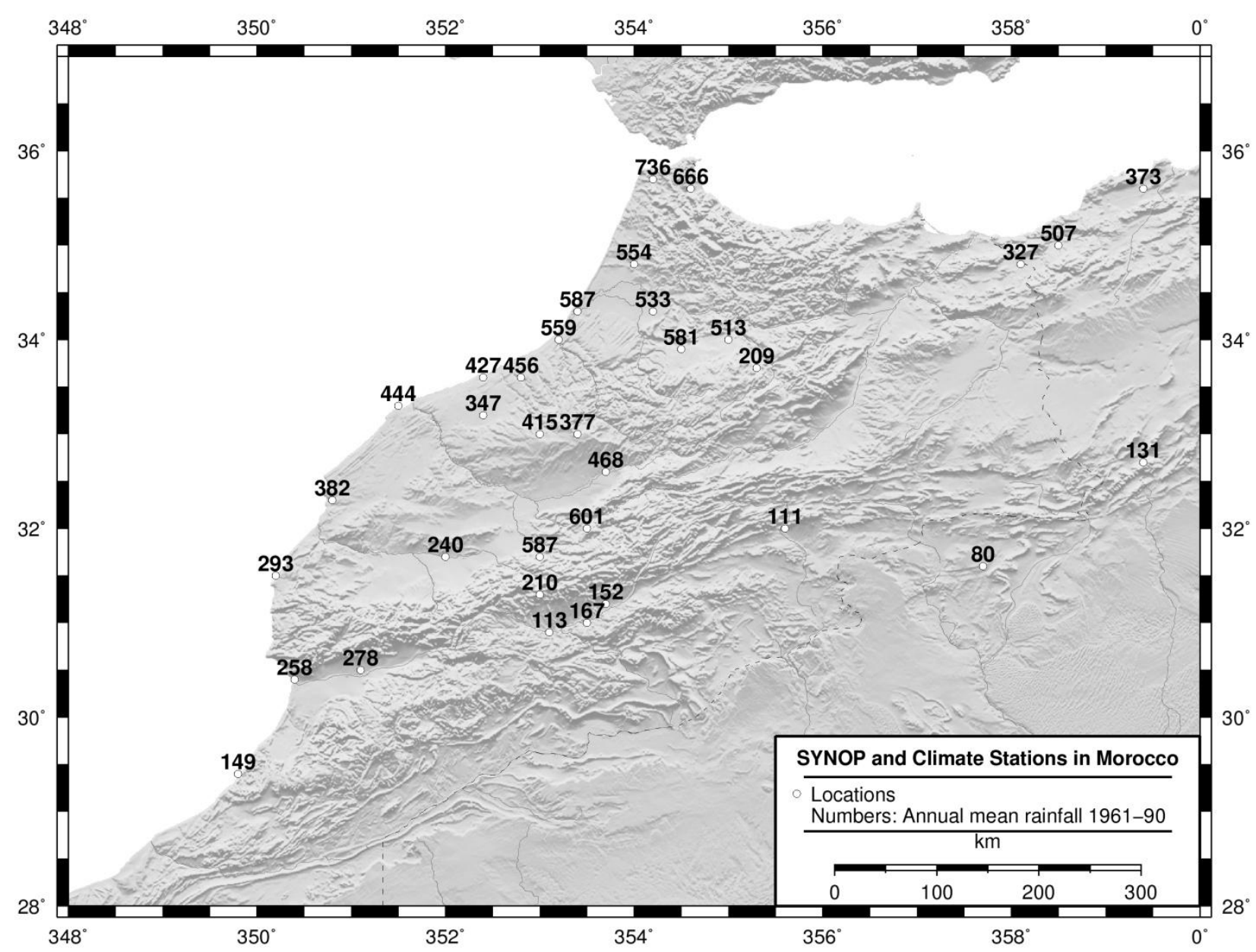

Fig.1: SYNOP Stations in Morocco and the western part of Algeria. Circles represent the locations of the stations, numbers the observed 1961-1990 mean annual rainfall sum in $\mathrm{mm}$.

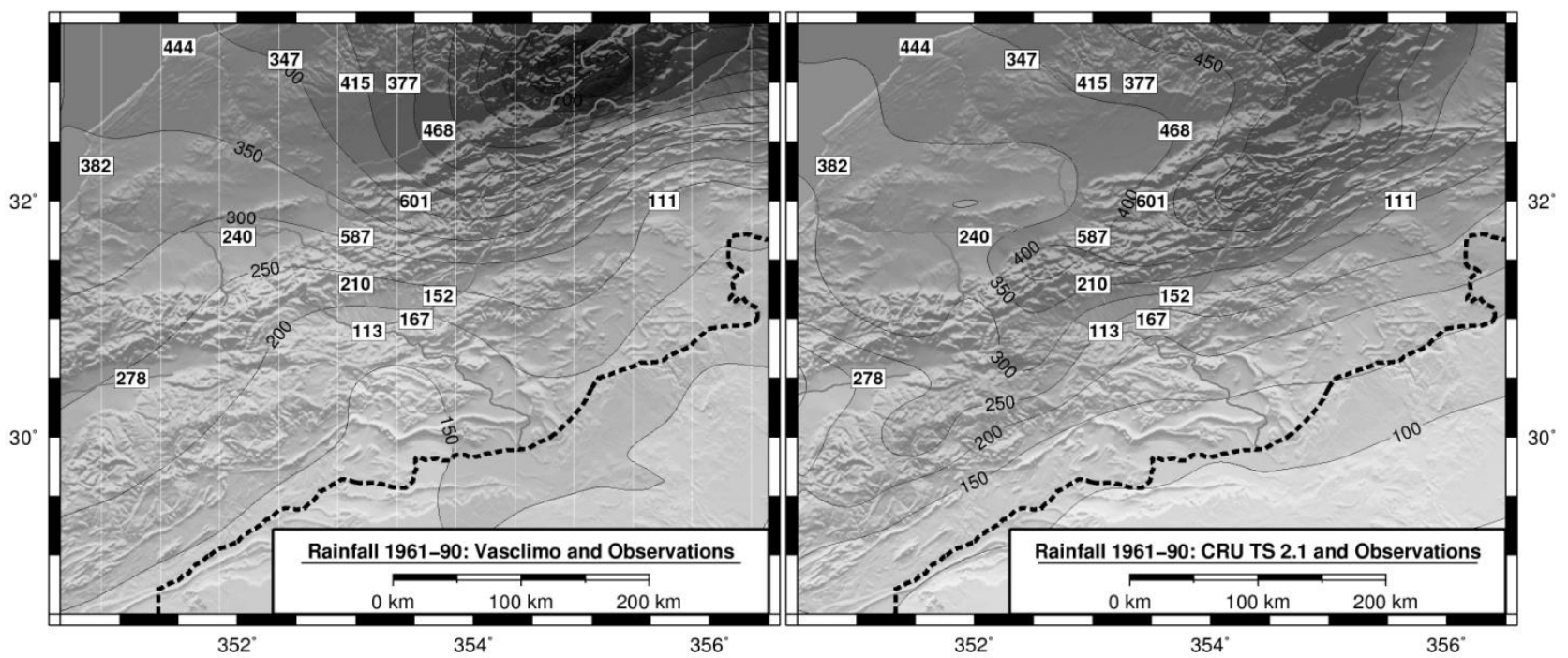

Fig. 2: Annual mean rainfall in $\mathrm{mm}$ (isolines with grey shading) for the period 1961-1990, as presented by the VASCLIMO data (left panel) and the CRU TS 2.1 data (right panel). The numbers in white rectangles show mean annual rainfall sums in the same period, but calculated directly from observations at SYNOP stations.

We begin with looking at the mean annual rainfall for the so-called climate normal period 1961-1990 (Fig. 2). In order to focus on the effect of orography and missing data, the annual mean rainfall is shown for a region centred on the High Atlas, which contains the area with more observations in the north and the area 
with hardly any observations in the south-east. Observations at stations were plotted as coloured circles in the map and allow a comparison with the interpolated products. In general, the CRU and VASCLIMO coincide very well with the observations, but in regions with less dense stations we can find larger differences. Interestingly, none of the data really represent the high precipitation in the Mountain region. The CRU data seems to accentuate the orographic effect on annual precipitation a little stronger, but overestimates the rainfall south of the Atlas. In the following, we have to keep this uncertainty in mind when looking deeper into the characteristics of climate-related parameters.

Climate variability affects vegetation in both natural and agricultural environments. Therefore, our second view focuses on the well known Köppen climate classification, which is based on thresholds relevant for special vegetation types. We want to demonstrate the climate shift in the late $20^{\text {th }}$ century by comparison of climate classes obtained from a reduced version of Köppens classification scheme, which has already proven its practicability in other applications (Guetter and Kutzbach, 1990, Fraedrich et al. 2001). Fraedrich et al. (2001) have shown that the - in a statistical sense - optimal length of time spans for detecting changes in the Köppen classification is 15 years. Therefore, classification is applied to the 15 -year periods 1951-65 and 1986-2000. Fig 3 shows the classification results for the entire Mediterranean basin. In northern Africa we can clearly see a shift towards dryer and warmer climates; at the borders to Steppe and Desert a number of pixels shift from moderate and summer dry $(C S)$ to Steppe climates. The Köppen classification is quite rough and only represents a very limited number of climate classes. Especially in the Cs region, a finer distinction is desirable.

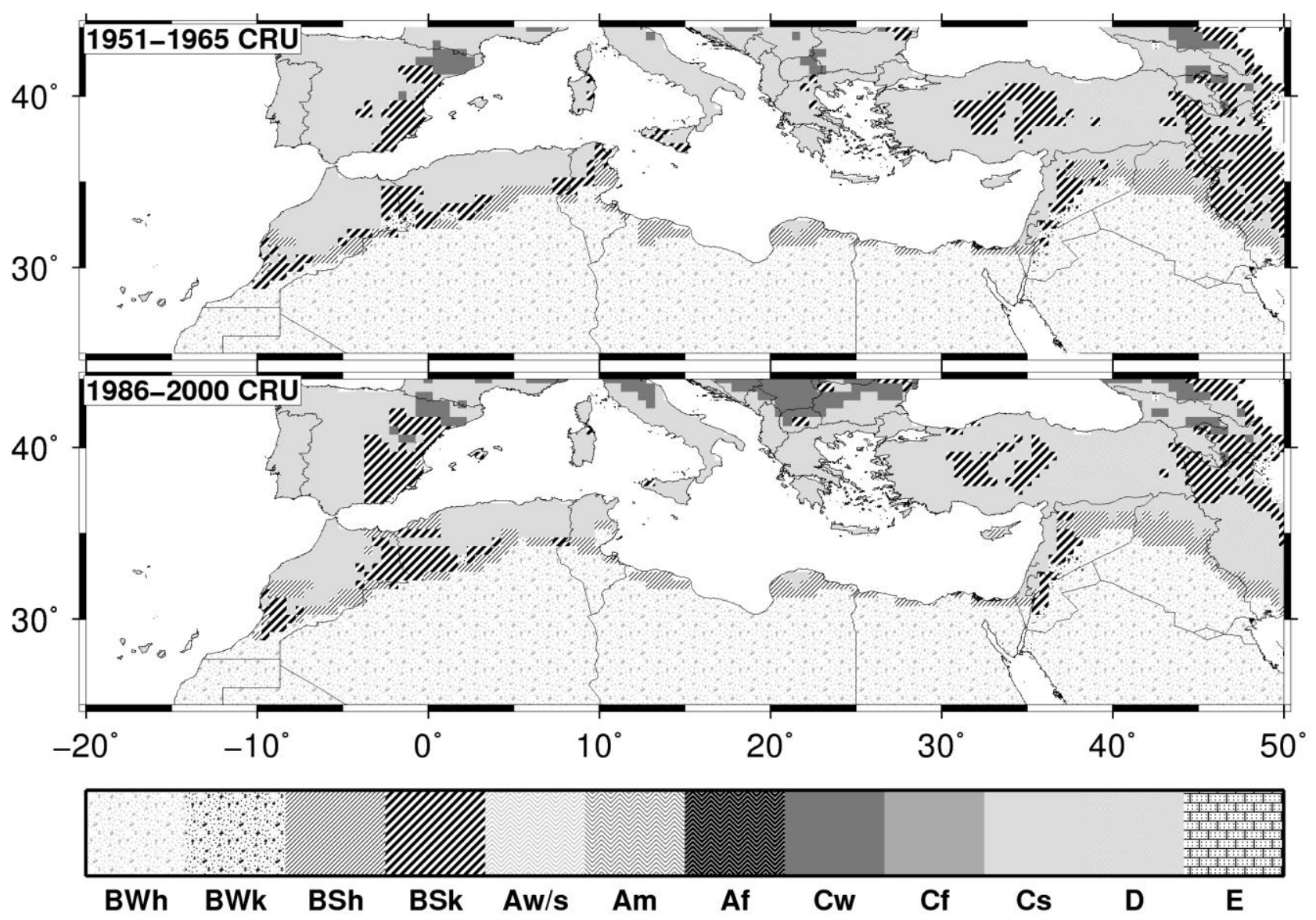

Fig. 3: Climate classification after a reduced Köppen scheme applied to the CRU TS2.1 data. The maps compare the climate classes for 1951-1965 to 1986-2000 and reveal a trend towards dryer and warmer climates in the second half of the $20^{\text {th }}$ century. 
Table 1: Definition of classes of the reduced Köppen climate classification. $T$ is the mean monthly temperature in $2 m$ hight above ground, Prec is the annual precipitation sum. Max / Min T indicate the warmest and coldest month in the mean annual cycle.

\begin{tabular}{|c|c|c|c|}
\hline Name & Climate & Criterion 1 & Criterion 2 \\
\hline $\mathbf{E}$ & Ice & $\operatorname{Max} \mathrm{T}<10^{\circ} \mathrm{C}$ & \\
\hline $\mathbf{D}$ & Snow & Max $\mathrm{T}>10^{\circ} \mathrm{C}$ and $\operatorname{Min} \mathrm{T}<-3^{\circ} \mathrm{C}$ & \\
\hline Cs & \multirow[t]{3}{*}{ Moderate } & $-3^{\circ} \mathrm{C}<\operatorname{Min} \mathrm{T}<18^{\circ} \mathrm{C}$ & summer dry \\
\hline Cf & & & Wet \\
\hline Cw & & & winter dry \\
\hline Af & \multirow[t]{3}{*}{ Tropical } & Min $\mathrm{T}>18^{\circ} \mathrm{C}$ & Wet \\
\hline Am & & & $\begin{array}{l}\text { Monsoon climate (dry period compensated by } \\
\text { seasonal rain) }\end{array}$ \\
\hline Aw/s & & & winter/summer dry \\
\hline BSk & \multirow[t]{2}{*}{ Steppe } & $\{$ Mean $T\}<\{$ Prec $\}<2\{$ Mean $T\}$ & cold $\left(\right.$ Mean $\left.\mathrm{T}<18^{\circ} \mathrm{C}\right)$ \\
\hline BSh & & & warm (Mean $\left.\mathrm{T}>18^{\circ} \mathrm{C}\right)$ \\
\hline BWk & \multirow[t]{2}{*}{ Desert } & cold with Mean $\mathrm{T}<18^{\circ} \mathrm{C}$ & \\
\hline BWh & & warm with Mean $\mathrm{T}>18^{\circ} \mathrm{C}$ & \\
\hline
\end{tabular}

The classification can be improved by merging orographic information and climate parameters statistically. As an example, we computed an aridity index by integrating the area between the mean annual march of temperature and rainfall in the Walter-Lieth diagram. The orographic information was included by a multiple linear regression of surface height and exposition (slope and direction) with rainfall and temperature. Then we divided the aridity index into eight classes and obtained the classification shown in Fig. 4. The Walter-Lieth climate diagrams according to the climate zones are also depicted. Here, the mountain climates and the northwest-southeast aridity gradient emerges clearly - also in regions where the Köppen classification showed only the CS climate. It has to be pointed out, however, that this purely statistical proceeding does not contain any information of regional and local scale weather systems of the mountain areas, which we expect to influence the near-surface climates. Ignoring these effects probably explains the overestimation of zone 4 south of the Atlas mountain ridge.

The third view focuses on the temporal climate variability. For this purpose, we look at the original observational data of SYNOP stations and combine them into regional indices. Since station-to-station differences in rainfall can be very large, we have first divided the monthly rainfall sums into 5 classes by separating the probability distribution - estimated simply by histograms - into quintiles, as recommended by the WMO No. 100 (1983). This way, each rainfall sum can be assigned to a number between 0 (no rainfall) and 5. These numbers are then averaged over regions with similar temporal behaviour of the rainfall (Fig. 5a). The regions were chosen with respect to typical rainfall bearing systems (Knippertz et al., 2003): The Atlantic region (ATL) is mainly affected by synoptic systems of the midlatitudes, has a seasonal rainfall maximum in the winter months (DJF) and is connected largely with the North Atlantic Oscillation (NAO). The Mediterranean region (MED) is also affected by Mediterranean pressure systems. Both regions are subhumid. The region south of the Atlas (SOA) is less affected by North Atlantic weather variability and gains rainfall relatively often from tropical-extratropical interactions. We have to notice, that the ATL region is represented by a larger number of stations - typical 25 - whereas the MED and SOA regions only contain about 5 stations.

In Fig. 5b, time series of rainfall indices for the winter months (Nov-Apr) are compared to CRU time series. The series are plotted as standardized anomalies to the 1961-1990 period. We can see, that for the ATL region winter rainfall variations (blue bars in the plot of the CRU data) are quite good in phase with the observations, but for the MED and SOA regions we can see larger differences. In this case, we tend to value the direct observations higher than the interpolated CRU product, because the latter contains also information from far away stations due to the employed statistical interpolation technique. The time series show periods of wet and dry years, which do not seem to be entirely random, but clustered in periods of 24 years. 


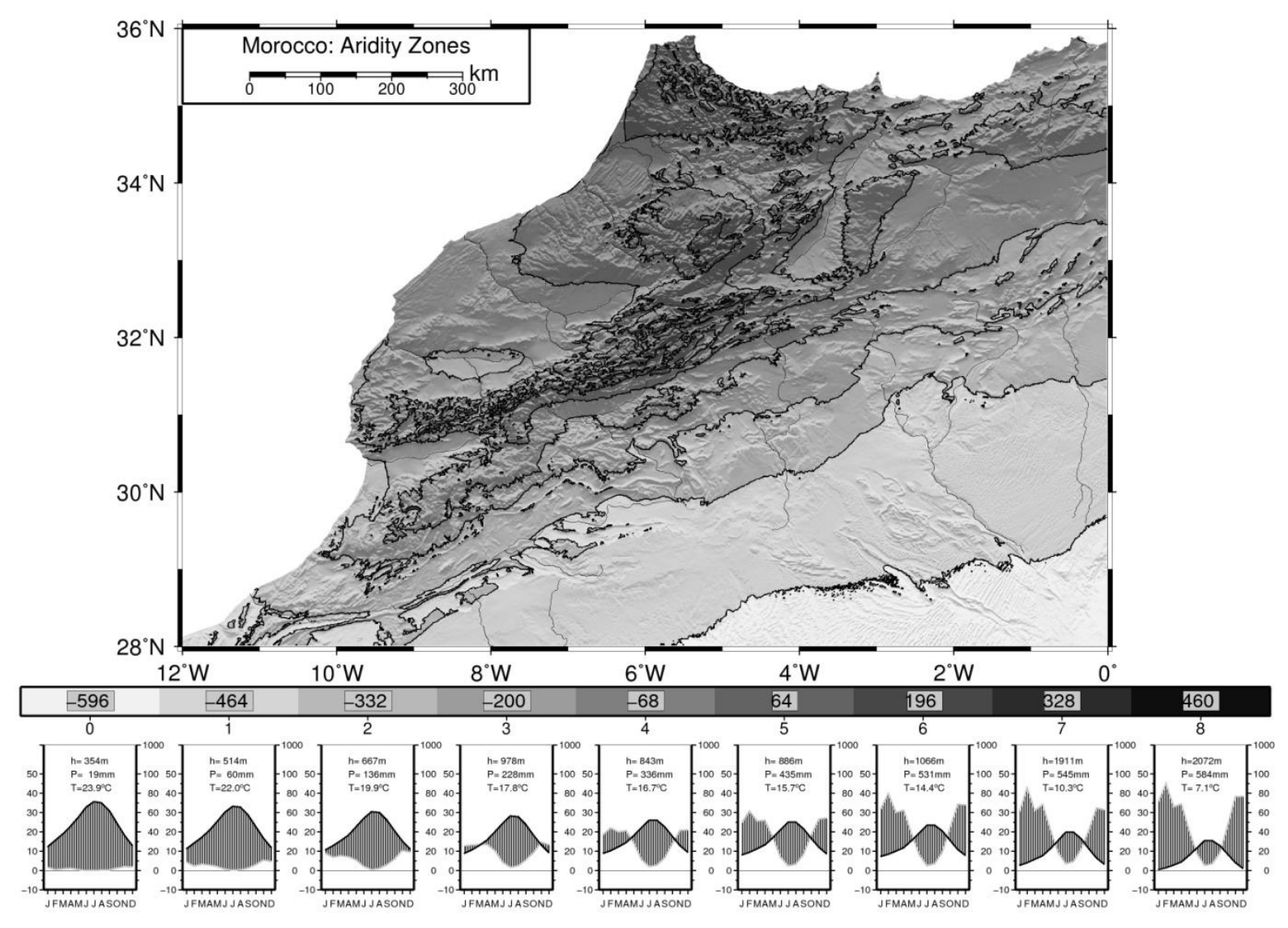

Fig. 4: Climate zones based on an aridity index computed as the aggregated difference of twice the temperature in ${ }^{\circ} \mathrm{C}$ and the rainfall for the averaged seasonal cycle. The Walter-Lieth diagrams (bottom) are representative for the zones. They show the annual cycle of temperature (black lines, right axis) and monthly rainfall sums (grey line, right axis). The numbers printed each diagram contains the average surface height, annual rainfall and annual mean temperature of each zone. The numbers in the grey scale bar are aridity indices for the zones. The data are collected from the 19611990 climate normal period. 
(a)

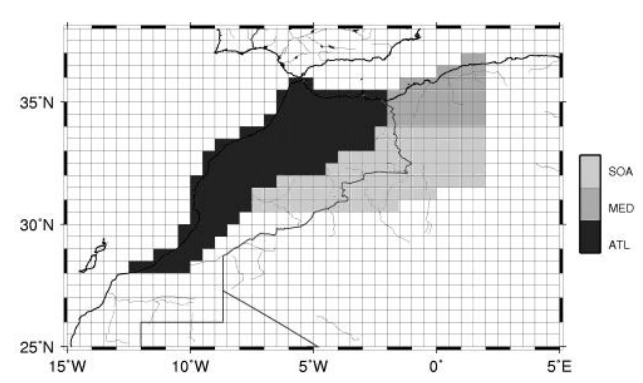

(b)
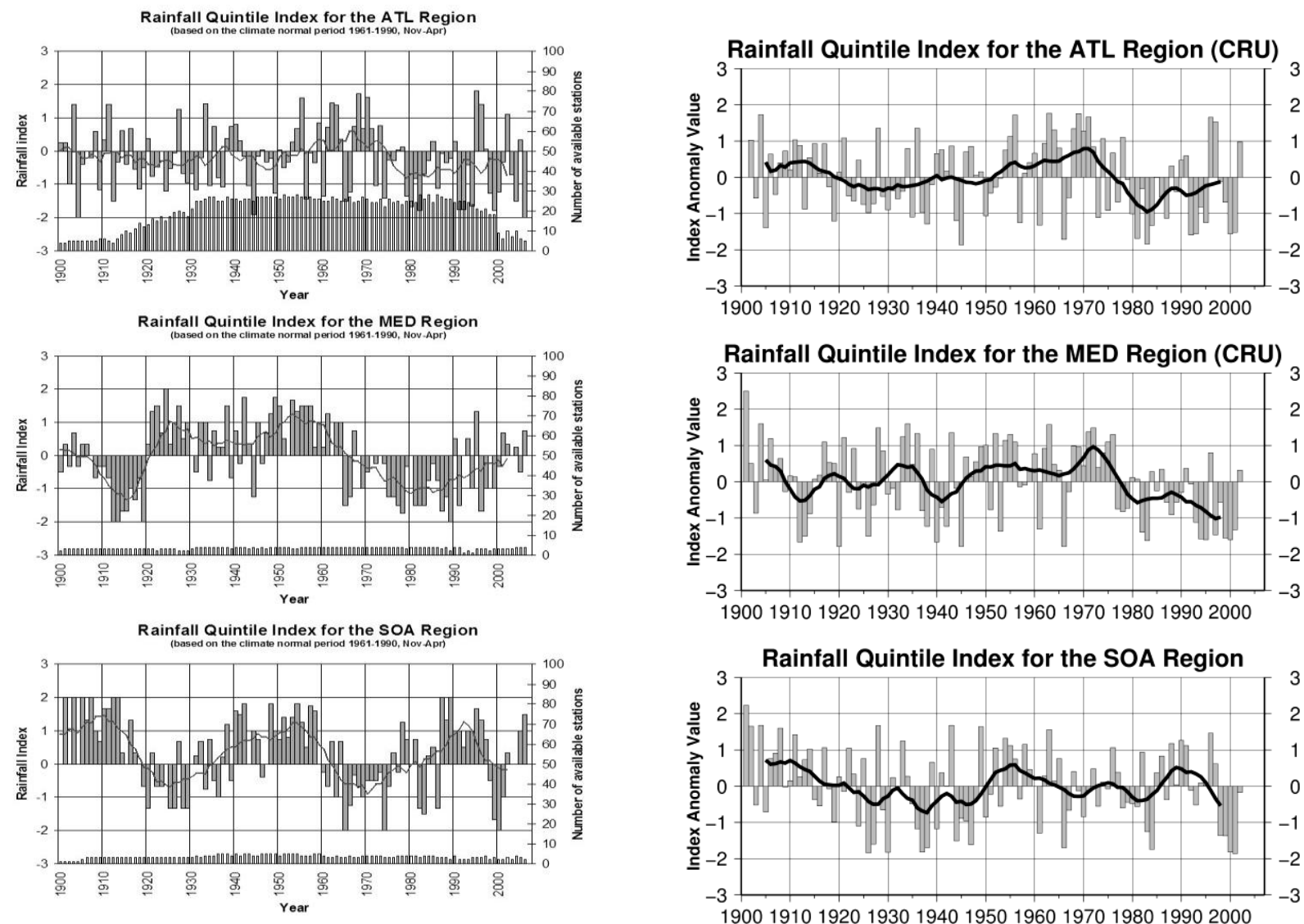

Fig. 5: (a) The Atlantic (ATL), Mediterranean (MED) and South-of-the-Atlas (SOA) regions, for which stations data were aggregated. (b) Rainfall indices based on quintiles for station data (left panels) and CRU TS 2.1, for the ATL, MED and SOA region, respectively. The left series are aggregated for the rainfall season (Nov-Apr) and correspond to the grey bars in the right panel. In addition, the graphics show filtered values (lines) and numbers of available stations.

\section{Concluding Remarks}

Utilizing observational data we took three different views on observed Moroccan rainfall climate. We have to admit that the quality and density of available observations causes a large range of uncertainty especially in the region south of the Atlas Mountains that is subject to large risks due to climate shifts. We can analyze the temporal variability of rainfall on long time scales and are able to identify periods of drought and of wet years. The Köppen climate classification clearly reveals the climate shift towards warmer and dryer climates in the $20^{\text {th }}$ century. Now, we have to walk a step ahead and ask for possible future developments. 


\section{Assessment of Future Climate in Morocco: Results from Regional Climate Modelling}

\section{Introduction}

A continuation of the observed trend, which we have shown in the previous chapter, implies changes in the temporal behaviour and strength of rainfall and, therefore, is expected to affect water availability and possibilities of a sufficient water distribution. Of course, this is of interest for long-term planning of regional and local facilities connected with water distribution.

In this chapter, results of recent regional climate modelling are presented with respect to the impact of climate change on vegetation and water availability in the three observational regions above defined: the Atlantic (ATL), Mediterranean (MED) and more desert-like climates south of the Atlas (SOA). First, to evaluate the RCM scenarios, the impact on near-surface conditions is shown by means of the Köppen climate classification, then characteristics of modelled rainfall index time series are shown.

\section{A Short Note on Climate Scenarios and Climate Models}

In order to assess the impact of future climate changes on the global scale, special computational models of the climate system have been developed by climate researchers in the past decades. They are based on physical principles and laws, mostly of the Earth's atmosphere but partly also to other climate subsystems like the pedosphere and the cryosphere. For atmospheric processes, Global Circulation Models (GCMs) have been applied to study the changes of climate parameters within the next century, mainly due to increasing greenhouse gas (GHG) contents in the atmosphere. This has been documented in several publications of the Intergovernmental Panel of Climate Change. They also reflect the proceeding of climate research over the last 15 or 20 years. One of the urgent issues of the $3^{\text {rd }}$ assessment report of the Intergovernmental Panel on Climate Change (IPCC, 1997 and IPCC, 2001) was the regionalisation or downscaling of GCM results, since it is well known that local conditions may be very different from what we observe on the large scale.

From GCM results of $21^{\text {st }}$ century climate scenarios, a continuation of the observed warming trend is expected for the subtropical regions. However, the prediction of rainfall is not as simple, since it is steered by teleconnections and local conditions as well. For the Atlas region, teleconnections can be seen e. g. with the Northern Atlantic Oscillation (NAO), tropical-extratropical interactions (TEI, Knippertz et al., 2003) and even with the El Niño/Southern Oscillation (ENSO). Local conditions are the land-sea distribution, the mountains and the state of the vegetation canopy.

Beneath the expert model, which uses the expertise of several climatologists to "interpret" GCM data on local regions, three more objective techniques have evolved to perform the downscaling of global scale climate data. (1) statistical downscaling, using statistical transfer functions between local observations and larger scale patterns obtained from reanalysis or GCM data (like we did for Fig. 4); (2) dynamical downscaling, using embedded finer scale regional climate models; and the mixture of both, known as (3) statistical-dynamical downscaling. Each of these methods has its own faults and advantages, which have to be identified and discussed when regional climate changes are estimated. For Morocco, the Atlas Mountains form a border between the desert climates of the Sahara and the moderate maritime climates. The dynamical downscaling performed by an application of a dynamic Regional Climate Model (RCM) embedded in atmospheric fields of GCM simulations, is expected to produce the most reliable results, as the model is able to simulate smaller scale circulations caused by the mountains.

\section{Models and Data}

The RCM has been undertaken with the Mesoscale Atmospheric Model REMO of the Max-Planck Institute for Meteorology (MPIfM) Hamburg. REMO is an atmospheric model based on the hydrostatic approximated set of hydrodynamic equations. The package of physical parameterizations is similar to the one of the ECHAM5 GCM in order to produce consistent results when REMO is nested into ECHAM5. The model area for this RCM approach contains North Africa and the Mediterranean $\left(15^{\circ} \mathrm{S}-45^{\circ} \mathrm{N}, 30^{\circ} \mathrm{W}-60^{\circ} \mathrm{E}\right)$. Further details of model physics are described in Jacob et al. (2001), the application of REMO for RCM in the Mediterranean and Africa has been presented in Paeth (2004), Paeth et al. (2005), and Paeth and Hense (2005). These studies focus on the evaluation of RCM data (Paeth, 2004 and Paeth et al., 2005) and the assessment of extreme events in the Mediterranean (Paeth and Hense, 2005). They are mainly based on the 
period 1979-2003 and forced by atmospheric data of the ECMWF (re-)analysis data. Because the RCM results were promising, REMO has been applied in ensemble mode for the period 2001-2050 in order to study the possible future development of climate in Northern Africa. For these model studies, the atmospheric forcing has been taken from coupled atmosphere and ocean modelling using the so-called Ocean-Atmosphere General Circulation Model (OAGCM) ECHAM5/MPI-OM (Roeckner et al., 2003). The scenarios of ECHAM5/MPI-OM participate in the $4^{\text {th }}$ IPCC report (IPCC, 2007). The climate forcing in REMO consists of the anthropogenic enhanced GHG effect and sea surface temperature (SST) changes, mainly inferred from the GCM, as well as land cover changes (LCC), which were assessed on the basis of FAO (Food and Agriculture Organization of the United Nations) studies. LCC is limited to Sub-Saharan Africa and contains the impacts of deforestation, desertification and the transition of natural vegetation into arable lands. It has to be kept in mind that the SST variability simulated by the OAGCM is not in phase with observed SST anomalies on shorter time scales. As a consequence, present day climate simulated with the OAGCM is not expected to coincide with observations of single years. Only the statistical characteristics of OAGCM simulations and longer-term conditions on typical climatic scales should resemble as much as possible.

State-of-the-art climate simulations perform for each climate scenario a couple of realizations, starting from different initial conditions, in order to give some information of system-immanent variability, which produces an uncertainty range of the climate simulations. The ensemble of REMO model simulations contains three control runs of the present day climate (1960-2000), three model runs of SRES scenario A1b (2001-2050) and three model runs of SRES scenario B1 (2001-2050). For the characteristics of the forcing in the SRES scenarios, see Fig. 6 . In order to separate the LCC-caused part of the climate change signal, another three model runs of SRES scenario A1b for 2001-2050 with fixed (but seasonally varying) vegetation have been undertaken. Further details and results are presented in Paeth et al. (2009).

(a) $\mathrm{CO}_{2}$ emissions

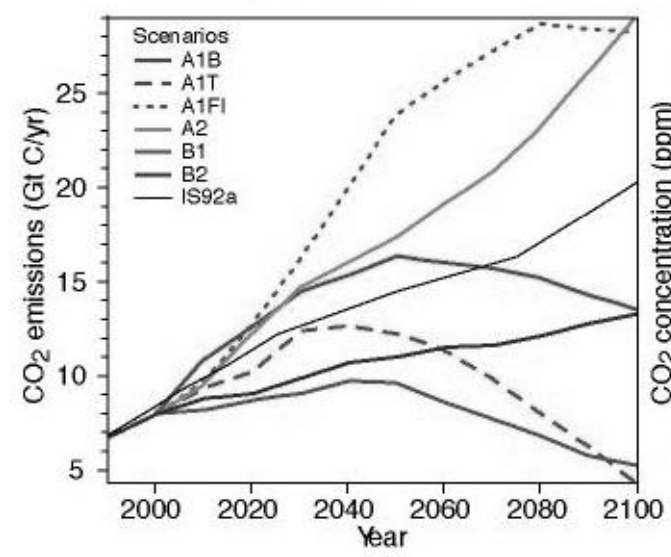

(b) $\mathrm{CO}_{2}$ concentrations

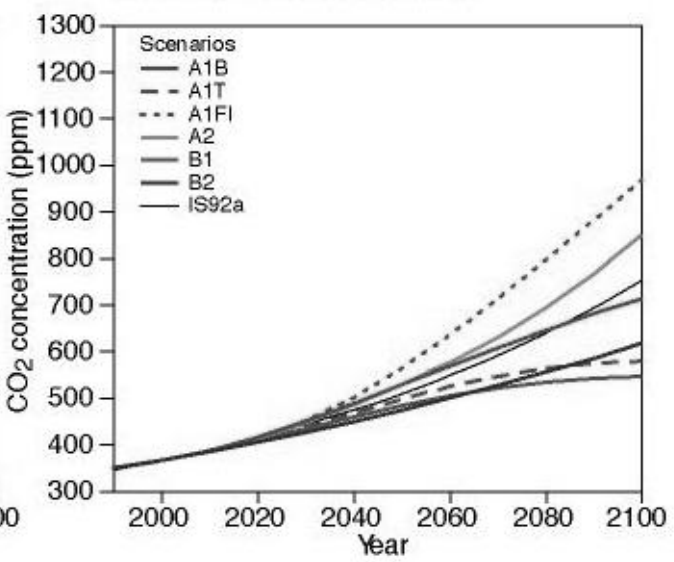

Fig. 6: CO2 emissions (left) and atmospheric concentrations (right) in SRES scenarios. Figure taken from IPCC (2001).

\section{Changing Climate in Terms of Koeppen-Geiger Climate Classification}

The application of the reduced Köppen classification to RCM data (Fig. 3) allows for a qualitative evaluation of the model bias as well as for an analysis of major climate changes. In former studies, the Köppen-Geiger classification has been applied to CRU data (Fraedrich et al., 2001, Kottek et al., 2006) as well as to GCM output (Guetter et al., 1990). For the REMO scenarios, the periods 1986-2000 and 2036-2050 are shown in Fig.7. Comparison with Fig. 3 reveals a slight model bias: In general, REMO simulates a dryer and warmer climate than CRU 2.1 data. For the future climate in 2036-2050, RCM shows a significant transition towards Steppe for the ATL and MED regions and towards desert in the SOA region. The changes - also in other parts of northern Africa, which are not shown here - are qualitatively similar to the observed changes in the $20^{\text {th }}$ century, albeit a little stronger.

In summary, the REMO model reveals a continuing and strengthening climate change towards dryer and warmer conditions all over Morocco. The warming is in accordance as well with $20^{\text {th }}$ century observations as with global temperature changes simulated by GCM climate scenarios. 


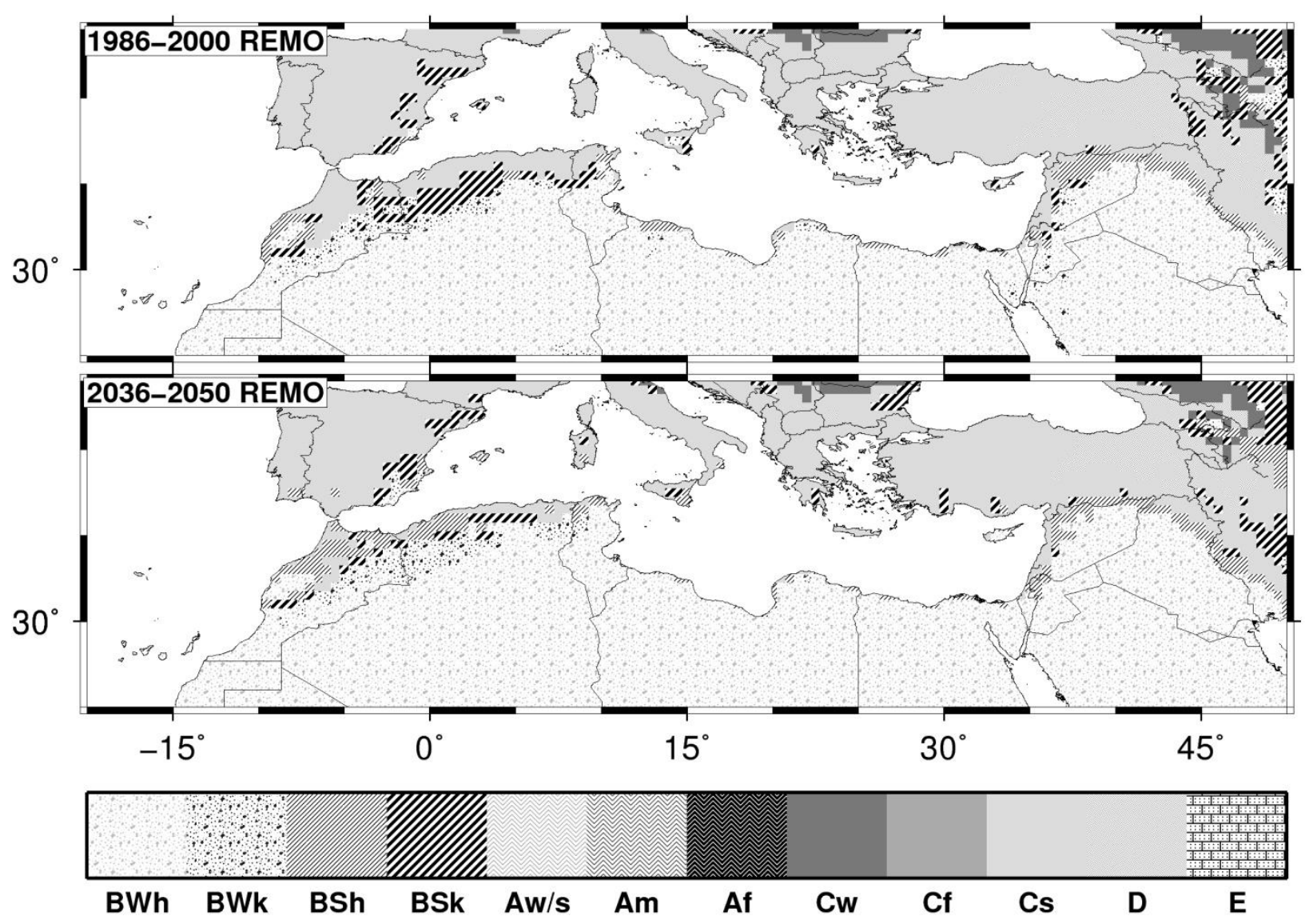

Fig. 7: Climate classification after Köppen for simulated climate scenarios from REMO.

\section{Rainfall in Future Climate Assessment}

Rainfall is the most important climate related component for the biosphere in general and for agriculture and vegetation in specific. Therefore, the estimation of future rainfall variability is essential and extremely valuable for any economic planning. But rainfall is also one of the most uncertain weather components. Even rainfall observations at stations, which are located relatively near to each other, may differ strongly. The value of rainfall observations as well as predictions might be enhanced by examining spatial and temporal averages. Therefore, the choice of the regions ATL, MED and SOA in Fig. 5a with similar statistic characteristics of rainfall for Morocco gives a somewhat more reliable view on rainfall variability in the climate scenarios and allows a comparison with CRU data (Fig. 5b). In Fig. 8, time series of the quintilebased rainfall index for the three regions are shown for one realization of the SRES-scenario A1b and - as a summarizing view - for all ensemble members, including the range of uncertainty calculated by the standard deviation of anomalies from the temporal filtered average of the ensemble mean. 

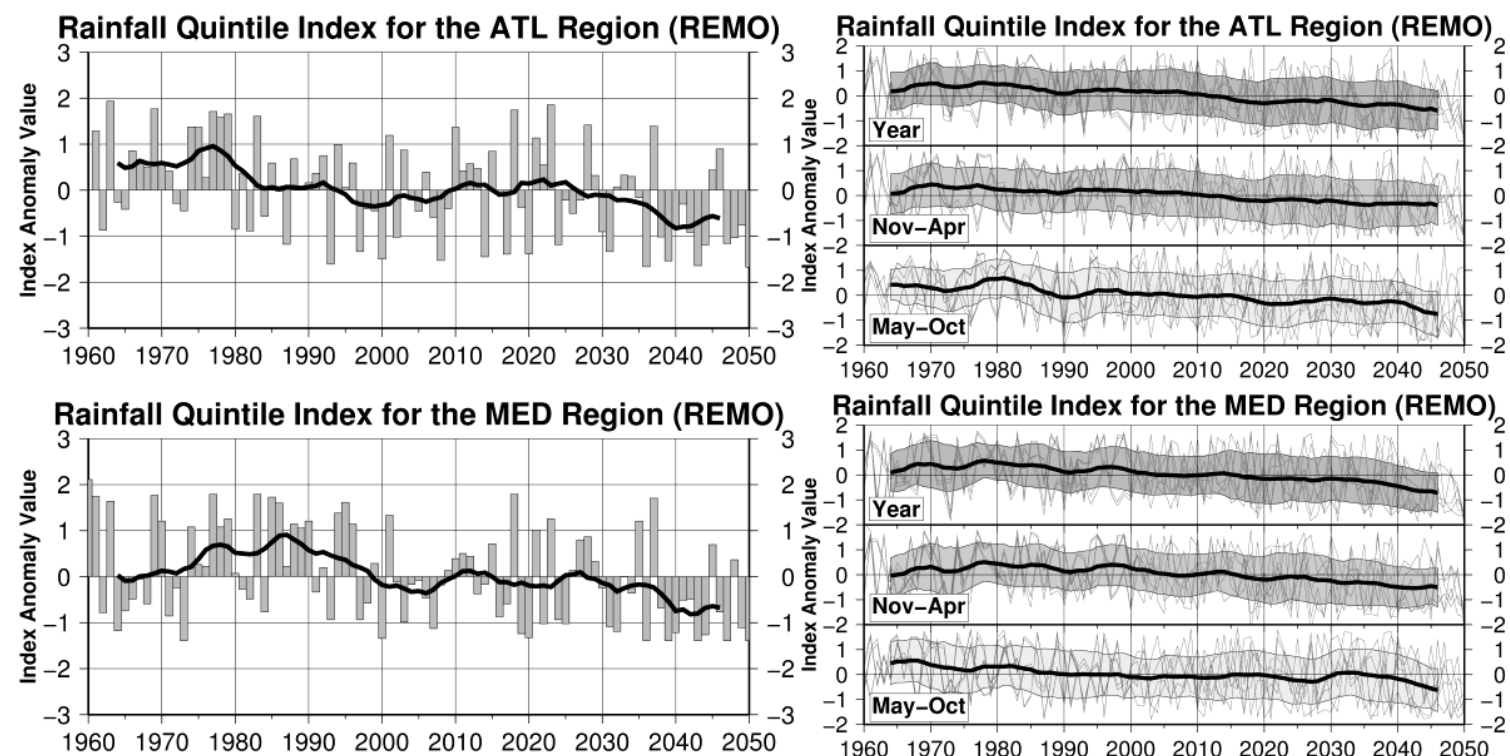

Rainfall Quintile Index for the MED Region (REMO),
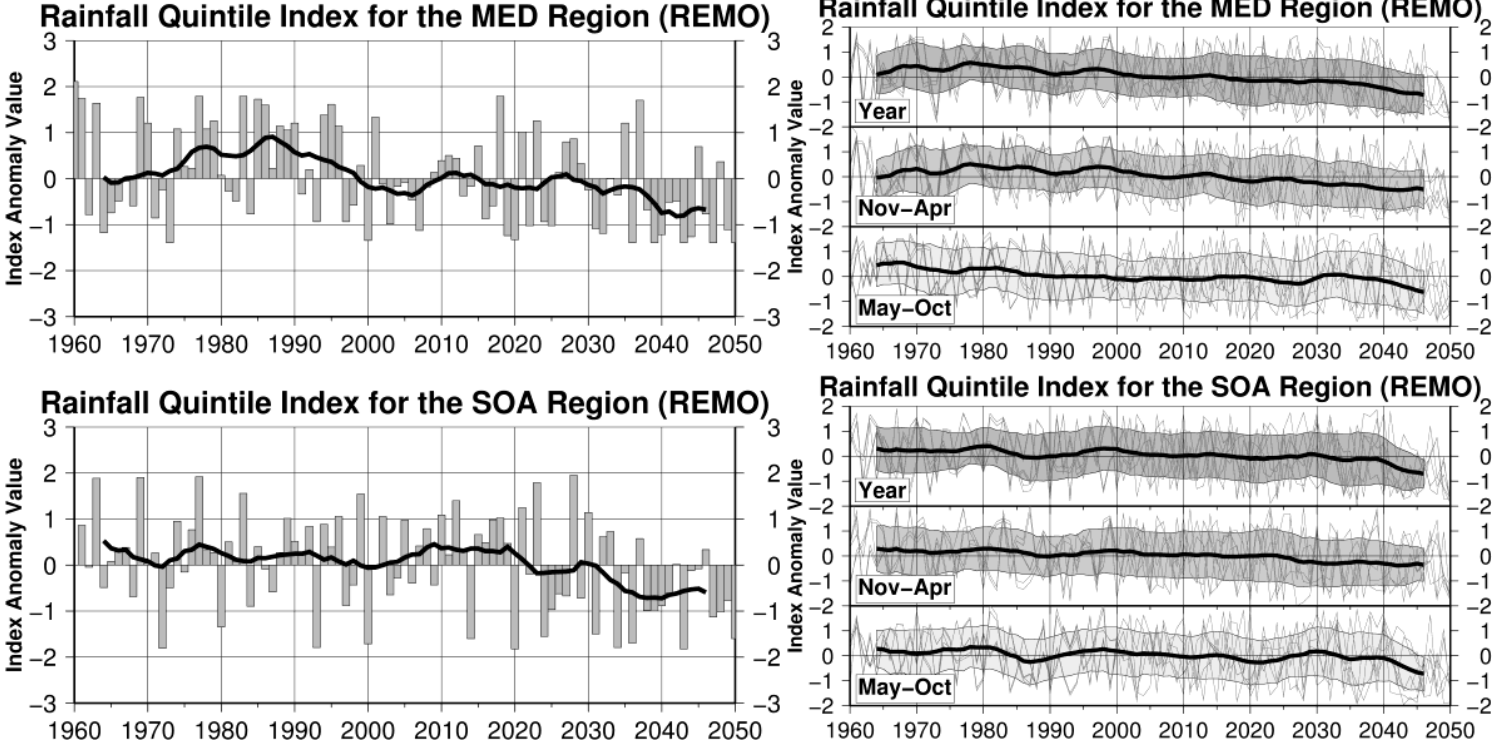

Fig. 8: Rainfall indices for the regions of interest in winter (NOV-APR) and summer (MAY-OCT). Left panel: Index series for the three regions for one realization of scenario SRES A1b, right panel: combined REMO scenarios A1b and B1, temporally filtered (5y filter width) and with uncertainty ranges (1 standard deviation, shaded regions) as a measure for system-immanent variability.

From a first view, it can be seen that a small, but statistically insignificant decrease in rainfall occurs. The decrease in annual rainfall sums reaches amounts of $25 \%$ from present day values, but the signal is hidden to a large part in interannual to decadal variability. In observations, the rainfall decrease was more prevalent for the winter season, whereas the model data show the decrease in winter and summer equally. An interesting detail is the decadal variability of the time series, which seems to be underestimated in the model data.

Table 2: Trend matrix for rainfall indices in standard deviation units / 91 years for the period 1960-2050. The bold values are trends, for which the error probability for rejection of the no-trend-hypothesis is smaller than $10 \%$. Additionally, trend uncertainties as mean deviations from the ensemble mean trend are given.

\begin{tabular}{|l|l|l|l|}
\hline Rainfall Index Trend & ATL & MED & SOA \\
\hline Winter & $-0.73 \pm 0.30$ & $-\mathbf{0 . 8 6} \pm 0.36$ & $-0.71 \pm 0.37$ \\
\hline Summer & $-0.73 \pm 0.42$ & $-0.46 \pm 0.38$ & $-0.63 \pm 0.41$ \\
\hline Year & $-\mathbf{0 . 9 1} \pm \mathbf{0 . 2 9}$ & $-\mathbf{0 . 9 1} \pm 0.25$ & $-\mathbf{0 . 8 3} \pm 0.26$ \\
\hline
\end{tabular}

The trend matrix for seasonal time series (Table 2) in the three regions reveals a slightly different behaviour in the regions. In the ATL region, rainfall is simulated to decrease by nearly one standard deviation of the index series within the years 2001-2050 of the combined scenario data A1B and B1. In the MED region, the decrease is more confined to the summer months, and in the SOA region, it is again similar in winter and summer. One has to keep in mind, that averaging over a number describing distinct classes is not a linear process, thus, the trend for annual sums is not just the average of the trends in the winter and summer 
months.

Nevertheless, the rainfall index shows a moderate linear trend towards less rainfall in all three regions, as we already expected from the analyses of the climate classification. The linear trends do - in general - not emerge from system-immanent (sometimes called "natural") variability of the RCM. This is revealed by the error probability of the rejection of the not-trend hypothesis, which is in all cases larger than $5 \%$. Thus, the signal-noise ratio is small, mainly because rainfall variability is very high in subtropical and partial semi-arid regions. The mutual range of the trend, calculated simply as averaged anomalies of the trends of single ensemble members, indicates that none of the scenario members shows a trend in the opposite direction, which increases the reliability of the findings a little bit. From the index series, we can draw conclusions regarding the relevance of changes in regional rainfall, although stations may have locally different rainfall sums. However, since the summer and winter indices use different rainfall distributions, they cannot be used to discuss changes in seasonality.

\section{Temperature in the Future Climate Assessment}

Temperature predictions for the future climate are somewhat less influenced by large spatial and temporal heterogeneity than rainfall (as long as we declare the height effect in the mountains as known and easily to describe). All simulations show a continuation of the observed warming trend and are statistically significant to a very high level. One impact of rising temperatures is the shift towards warmer climate classes as discussed in the foregoing chapters. One of the strongest impacts could be the rise of the snowline in the Atlas Mountains, since the amount of water stored in snow is important for runoff characteristics of single events as well as for seasonal values, since snowmelt can contribute to the available water for agriculture and households in the beginning of the dry season. Thus, temperature trends have been calculated for the winter and summer season, respectively. It reveals a stronger warming trend in the summer months than in winter, which means a more "continental" behaviour with a strong spread between summer and winter conditions. On the other hand, the expected rise of the snowline, estimated roughly from the simulated warming and standard atmosphere conditions is not as strong as suggested by the annual values, since we assume that snowfall mainly occurs in winter months, where the warming is less pronounced than in summer. Nevertheless, the warming is responsible for a shift from Steppe towards desert climates in the Köppen climate classification (Fig. 7).

The time series of $2 \mathrm{~m}$-temperatures for the combined simulated A1b and B1 scenarios (Fig. 9) shows, similar to the negative rainfall trend, a continuation of the warming already observed in the $20^{\text {th }}$ century, The trend matrix is shown in Table 3. Different from rainfall, linear temperature trends are nearly all highly significant and reach an error probability of rejecting the null-trend hypothesis of less than $1 \%$.

The trend matrix clearly shows a distinct behaviour in summer and winter: the warming seems to be stronger in summer time. Regarding a supposed snowline rise, a more detailed analysis is necessary, because temporal correlation between rainfall and temperatures has to be taken into account.

Table 3: Trend matrix for temperature in K/91 years from REMO A1b and B1 scenarios, for the period 1960-2050. For all values, the error probability for the rejection of the no-trend-hypothesis is less than $1 \%$. Again, the range of uncertainty is given as the averaged deviation from the ensemble mean trend.

\begin{tabular}{|l|l|l|l|}
\hline Temperature trend & ATL & MED & SOA \\
\hline Winter & $1.37 \pm 0.28$ & $1.33 \pm 0.22$ & $1.27 \pm 0.18$ \\
\hline Summer & $1.75 \pm 0.49$ & $2.04 \pm 0.55$ & $2.02 \pm 0.52$ \\
\hline Year & $1.56 \pm 0.29$ & $1.69 \pm 0.31$ & $1.64 \pm 0.29$ \\
\hline
\end{tabular}



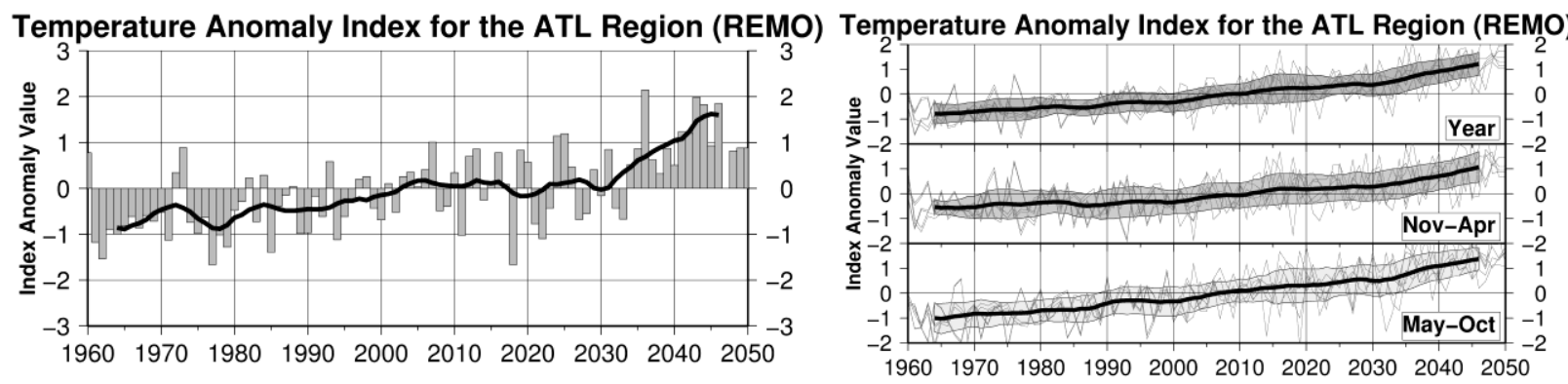

Temperature Anomaly Index for the MED Region (REMO)
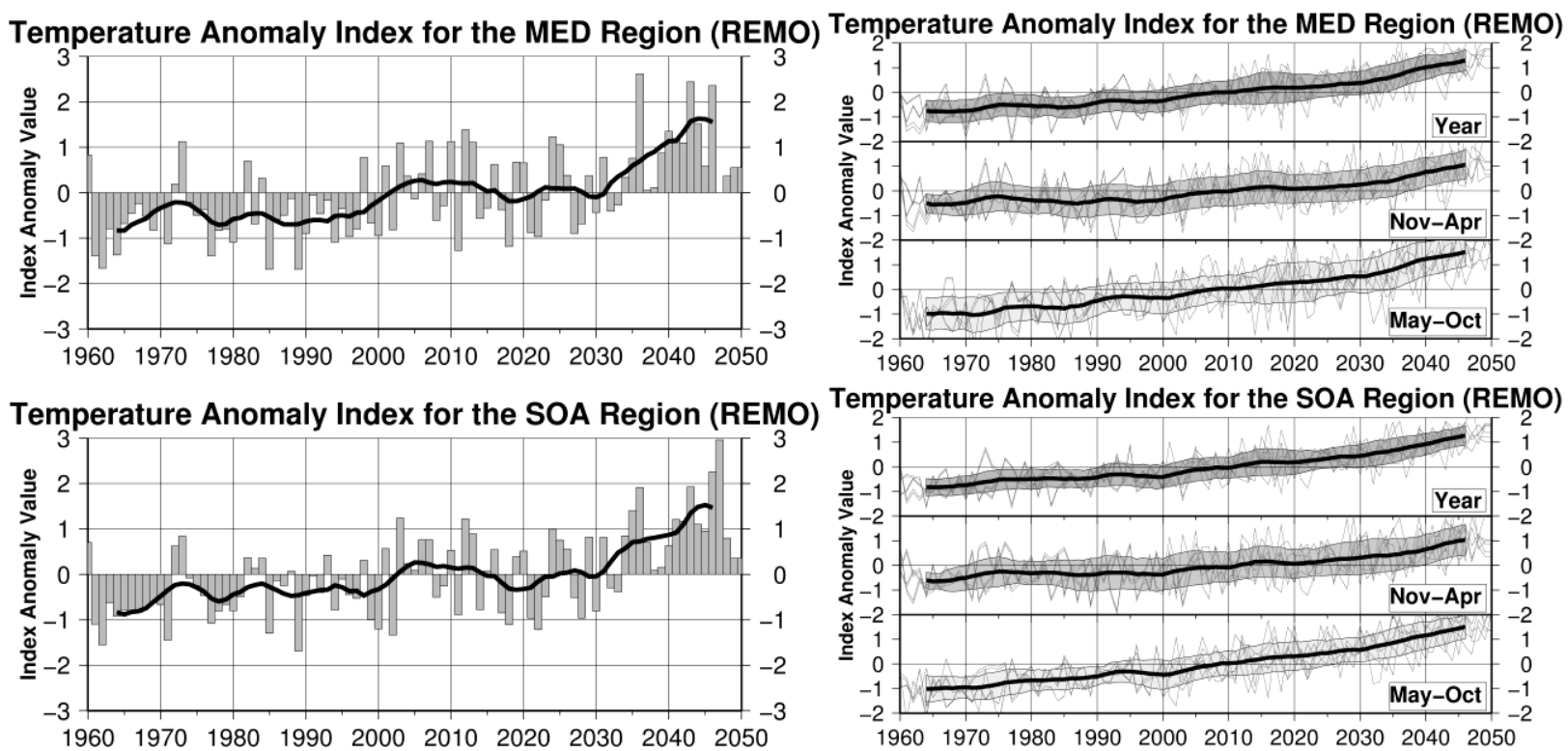

Fig. 9: Time series of spatial averages of near surface temperature ( $2 \mathrm{~m}$ height) in $K$, as obtained from one ensemble member of the REMO climate scenarios SRES A1b (left) and as filtered time series(11-year filter width) with added uncertainty ranges for all REMO climate scenarios $A 1 b$ and $B 1$ (right).

\section{Conclusions}

Moroccan climate has been described by examination of observational values, both directly from stations as from the interpolated products of CRU TS2.1 and VASCLIMO. It turned out that the data are very sparse in regions, where the future climate shift is expected to have the largest impact on humans and vegetation. Nevertheless, the $20^{\text {th }}$ century data revealed a warming and drying trend in terms of the vegetation relevant Köppen climate classification.

In order to allow for an outlook into future climate conditions, rainfall and temperature variability in present day and for future climate scenarios were estimated by an RCM approach. The analysis of the results points to a continuation of the trend observed in the $20^{\text {th }}$ century. The RCM scenarios show reliable results, although a model bias towards dryer climates can be seen. The existence of this model bias is - due to the high complexity of the simulated processes - not very surprising. It has to be taken into account when interpreting the results and might be used in future research to identify sections, where the description of the climate system could be improved.

The results of our study have to be slightly restricted. Since there exists no other set of RCM scenarios covering Northern Africa with such a high resolution, our results will have to be carefully tested with other regional climate models in future climate research.

The RCM results show a trustworthy and acceptable range of uncertainty. Although differences in long-term variability between observations and model data can be seen, the uncertainty due to system-immanent (natural) variability seems to be quite realistic. Thus, the effect of global scale greenhouse gas forcing and land cover changes in Africa (which were not discussed separately in this study, but were both part of the climate change forcing in the RCM approach) on regional Moroccan climate can be assessed from RCM scenarios. The most prominent change is a shift of all climates towards warmer and dryer conditions and, therefore, a further increase in the existing water stress is expected, especially south of the Atlas Mountains. 


\section{Acknowledgements}

This work was supported by the Federal German Ministry of Education and Research (BMBF) under grant No. 01 LW 06001A and by the Ministry of Innovation, Science, Research and Technology (MIWFT) of the federal state of Northrhine-Westfalia under grant No. 313-21200200.

The observational data were collected and maintained under the participation of Tim Brücher and Kristina Piecha from the Institute for Geophysics and Meteorology of the University Cologne. Robin Girmes and Kai-Oliver Heuer, who were involved in the IMPETUS project, have supplied model data management. Ralf Podzun and Daniela Jacob, Max-PanckInstitute for Meteorology in Hamburg, have realized the RCM model runs at the Deutsches Klimarechenzentrum.

\section{References}

Fraedrich, K., F.-W. Gerstengarbe and P. C. Werner, 2001: Climate shift during the last century. Climatic Change 50, 405417.

Beck, C., J. Grieser and B. Rudolf (2005): A New Monthly Precipitation Climatology for the Global Land Areas for the Period 1951 to 2000. Published in Climate Status Report 2004, pp. 181 - 190, German Weather Service, Offenbach, Germany

Guetter, P. J. and Kutzbach, J. E., 1990: A modified Koeppen classification applied to model simulations of glacial and interglacial climates, Clim. Change 16, 193-215.

IPCC, 1997: The Regional Impacts of Climate Change: An Assessment of Vulnerability. A Special Report of IPCC Working group II. Eds: Watson, R. T., M. C. Zinyowera, R. H. Moss. Cambridge University Press, UK, 517pp.

IPCC, 2001:Climate Change 2001: Impacts, Adaptation \& Vulnerability. Contribution of Working Group II to the Third Assessment Report of the Intergovernmental Panel on Climate Change (IPCC). Eds: James J. McCarthy, Osvaldo F. Canziani, Neil A. Leary, David J. Dokken and Kasey S. White, Cambridge University Press, UK. 1000pp.

IPCC, 2007: IPCC Fourth Assessment Report (AR4) Working Group I Report "The Physical Science Basis", available online http://ipcc-wg1.ucar.edu/wg1/wg1-report.html (Sep 16, 2007), about to appear in Nov. 2007.

Jacob, D., Van den Hurk, B.J.J.M., Andrae, U., Elgered, G., Fortelius, C., Graham, L.P., Jackson, S.D., Karstens, U., Koepken, C., Lindau, R., Podzun, R., Rockel, B., Rubel, F., Sass, B.H., Smith, R. and Yang, X., 2001, A comprehensive model intercomparison study investigating the water budget during the PIDCAP period. Meteorol. Atmos. Phys. 77: 1944.

Knippertz, P.; Christoph, M.; Speth, P., 2003: Long-term precipitation variability in Morocco and the link to the largescale circulation in recent and future climates. Meteorology and Atmospheric Physics, 83, 67-88.

Kottek, M., J. Grieser, C. Beck, B. Rudolf, and F. Rubel, 2006: World map of the KöppenGeiger climate classification updated. Meteorol. Z., 15, 259-263.

Mitchell, T. D., and P. D. Jones, 2005: An improved method of constructing a database of monthly climate observations and associated high resolution grids. Int. J. Climatol. 25, 693-712.

Paeth, H., 2004, Key factors in African climate change evaluated by a regional climate model. Erdkunde 58, $290-315$.

Paeth, H., Born, K., Podzun, R. and Jacob, D., 2005, Regional dynamic downscaling over West Africa: Model evaluation and comparison of wet and dry years. Meteorol. Z. 14, 349-367.

Paeth, H. \& Hense, A., 2005, Mean versus extreme climate in the Mediterranean region and its sensitivity to future global warming conditions. Meteorol. Z. 14, 329-347.

Paeth, H., K. Born, R. Girmes, R. Podzun and D. Jacob, 2009: Regional Climate change in tropical and northern Africa due to greenhouse forcing and land use changes. J. Climate, in press.

Roeckner, E. et al. The atmospheric general circulation model ECHAM 5. PART I: Model description. MPI-Report 349, 127pp (2003).

World Meteorological Organization, 1983: Guide to climatological practices. Secretariat of the World Meteorological Organization, Geneva, Switzerland. WMO No. 100, Second Edition 1983, 198 pp. 